\author{
Submitted: \\ 29.07.2018 \\ Accepted: \\ 04.11.2018 \\ Published: \\ 31.12 .2018

\section{Comparison of high resolution ultrasonography with clinical findings in patients with ankle pain} \\ Kunwarpal Singh, Chuni Lal Thukral, Kamlesh Gupta, Avtar Singh \\ Department of Radiodiagnosis and Imaging, Sri Guru Ram Das University of Health Sciences, \\ Vallah, Sri Amritsar, Punjab, India \\ Correspondence: Dr. Kunwarpal Singh, S/O S. Balbir Singh, H.NO.1753/VII-12, Bazar \\ Ghumiaran, Chowk Chabutra, Opposite Darshan Maternity Home, Inside Gilwali Gate, \\ Amritsar, Punjab, India; tel.: +911832526426, e-mail:kpsdhami@gmail.com \\ DOI: $10.15557 / J o U .2018 .0046$ \\ Keywords \\ ultrasonography, \\ ankle joint, \\ ligaments, \\ tendons

\begin{abstract}
Aim: The aim of this study was to investigate the diagnostic accuracy of high resolution ultrasonography for the assessment of painful ankle joint as compared with the clinical findings. Material and Methods: A prospective study was conducted on 136 patients having history of ankle pain and referred to the Department of Radiodiagnosis and Imaging for ultrasonography. Statistical analysis: Comparison of ultrasonography findings and clinical findings was done using McNemar Test. Results: 136 patients with 218 pathologies of the ankle joint were analyzed. Of these, 178 pathologies were clinically suspected, but 206 were diagnosed with ultrasonography. This difference was statistically significant ( $p$ value $=0.000)$. Conclusion: Ultrasonography is an excellent tool for evaluating patients with ankle pain, especially in cases of lateral ligament pathologies, tendinous pathologies, joint effusion, and miscellaneous pathologies. It can be used as the primary imaging investigation because it allows a rapid, dynamic, and cost-effective examination of the ankle joint. However, ultrasonography has limitations when using it to evaluate a suspected posterior talofibular ligament injury, marrow abnormalities, and deep seated pathologies, for which MRI should be incorporated for a diagnosis.
\end{abstract}

\section{Introduction}

The ankle joint is the articulation between the dome of the talus and the distal tibia and fibula ${ }^{(1)}$. The most common clinical presentation of patients with ankle pathology is pain and swelling, followed by pain alone ${ }^{(2)}$. The differential diagnosis includes trauma, inflammation, infection, and degeneration. Detailed history and careful clinical assessment are very important. Restriction in certain movements may serve as an indirect clue to the anatomical structure involved ${ }^{(3)}$.

Various clinical tests can be used to evaluate the integrity of ligaments and tendons ${ }^{(3)}$ (Tab. 1). Different diagnoses unfortunately tend to have overlapping clinical signs and symptoms. For this reason, referring clinicians tend to rely on imaging ${ }^{(3)}$.

Plain radiographs are the first-line tool in imaging technology, but visualizing soft tissue pathologies is not very clear and may require ultrasound or magnetic resonance imaging ${ }^{(4)}$.

Ultrasonography (US) has many benefits for evaluating ankle pain, especially the superficial structures including tendons, ligaments, and nerves. Stress US helps to differentiate partial from complete ligament tears ${ }^{(3,5)}$.

Magnetic resonance imaging (MRI) has emerged as a good modality for the diagnosis of musculoskeletal diseases of the ankle and foot, especially the deeper structures. However, it is relatively more time-consuming and less costeffective, compared with $\mathrm{US}^{(6,7)}$.

\section{Normal tendo-ligamentous anatomy}

The normal tendo-ligamentous anatomy of the ankle joint is described in Tab. 2. 


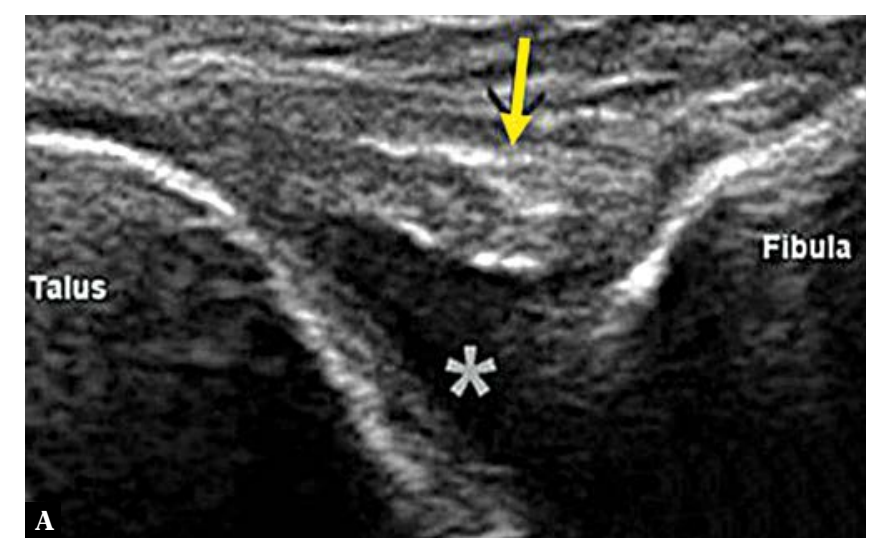

Fig. 1. US image of a 27-year-old male patient with a history of road side accident 3 days back shows thickened anterior talofibular ligament (ATFL) in the neutral position (arrow in $\mathbf{A})$. Stress maneuver shows thickened ATFL (green arrow in $\mathbf{B}$ ) with non-visualization of fibers near its fibular end (red arrow); suggestive of grade III tear. Surrounding free fluid is also seen, appearing as anechoic area (marked with an asterisk)

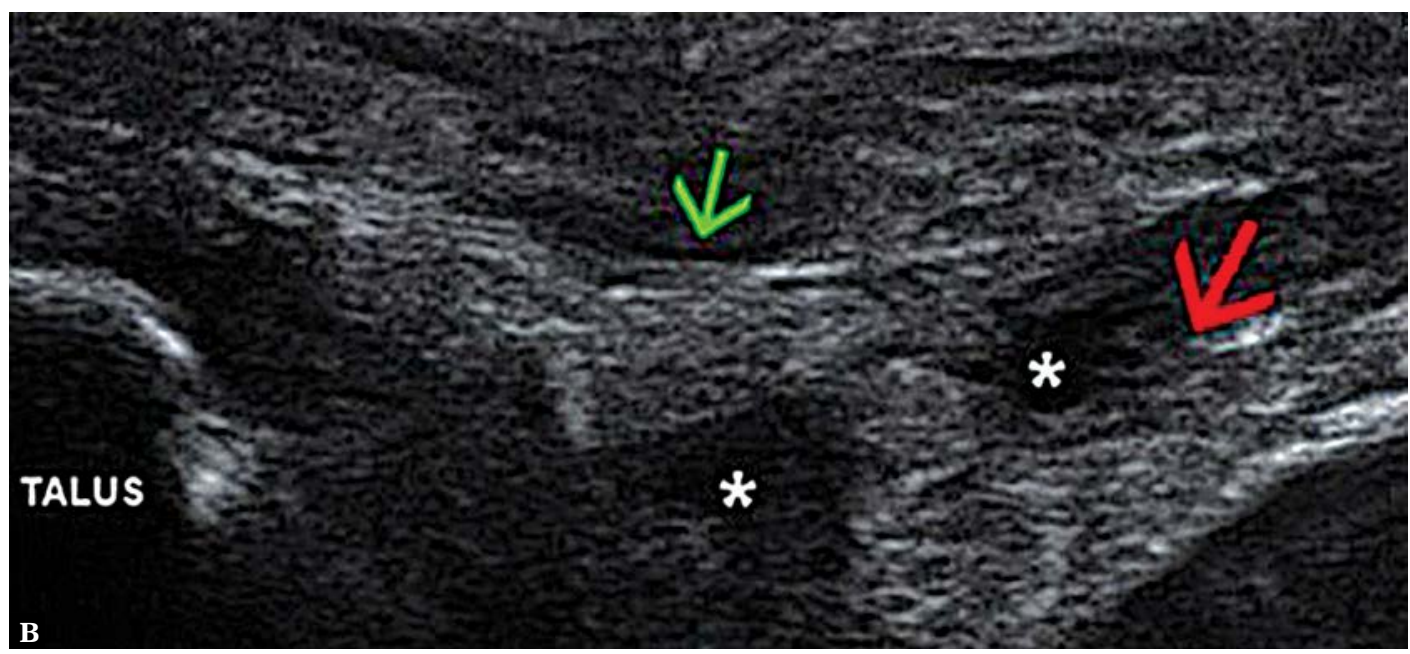

\begin{tabular}{|c|c|c|c|}
\hline Name of the test & Technique & Interpretation & $\begin{array}{l}\text { Ligament/tendon } \\
\text { evaluated }\end{array}$ \\
\hline Anterior drawer test & $\begin{array}{l}\text { An examiner uses one hand to hold } \\
\text { the patient's heel and the opposite } \\
\text { hand to stabilize the anterior } \\
\text { portion of the distal tibia and } \\
\text { fibula. The examiner then uses the } \\
\text { hand on the heel to pull the foot } \\
\text { anteriorly. }\end{array}$ & $\begin{array}{l}\text { The test is abnormal when } \\
\text { translation on the affected side is } \\
3-5 \mathrm{~mm} \text { greater than that on the } \\
\text { normal side. }\end{array}$ & $\begin{array}{l}\text { Anterior talofibular } \\
\text { ligament (ATFL) }\end{array}$ \\
\hline $\begin{array}{l}\text { The inversion } \\
\text { stress test }\end{array}$ & $\begin{array}{l}\text { The examiner uses one hand to cup } \\
\text { the heel of the affected foot and } \\
\text { the opposite hand to stabilize the } \\
\text { anterior portion of the distal tibia } \\
\text { and fibula. } \\
\text { The ATFL is evaluated by maximally } \\
\text { plantarflexing the ankle and } \\
\text { then inverting the rear foot; } \\
\text { laxity and pain should occur. } \\
\text { The calcaneofibular ligament } \\
\text { is evaluated by maximally } \\
\text { dorsiflexing the foot and then } \\
\text { inverting the rear foot. }\end{array}$ & $\begin{array}{l}\text { The test is abnormal when } \\
\text { inversion on the affected side is } \\
\text { 10-15 degrees greater than that of } \\
\text { the opposite side. }\end{array}$ & $\begin{array}{l}\text { Lateral ligaments } \\
\text { complex }\end{array}$ \\
\hline The Thompson test & $\begin{array}{l}\text { If the foot does not plantarflex, } \\
\text { rupture of the Achilles tendon must } \\
\text { be considered. }\end{array}$ & $\begin{array}{c}\text { Jeśli stopa nie jest w zgięciu } \\
\text { podeszwowym, należy } \\
\text { podejrzewać zerwanie ścięgna } \\
\text { Achillesa. }\end{array}$ & $\begin{array}{l}\text { Complete rupture of the } \\
\text { Achilles tendon }\end{array}$ \\
\hline
\end{tabular}

Tab. 1. Various clinical tests with techniques to assess the integrity of ligaments and tendons of the ankle joint 


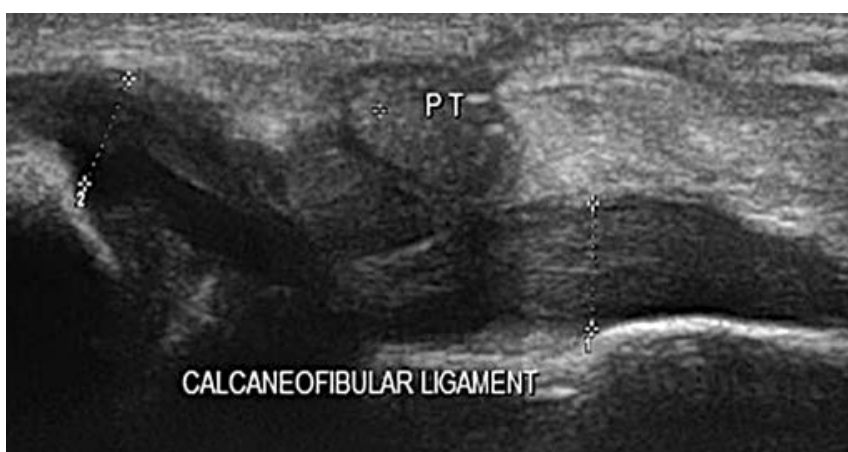

Fig. 2. US image of a 43-year-old male patient with a history of inversion injury 1 day back shows thickened and hypoechoic calcaneofibular ligament (CFL). Mild thinning of fibers near the fibular end is seen with surrounding small amount of free fluid; suggestive of grade II tear
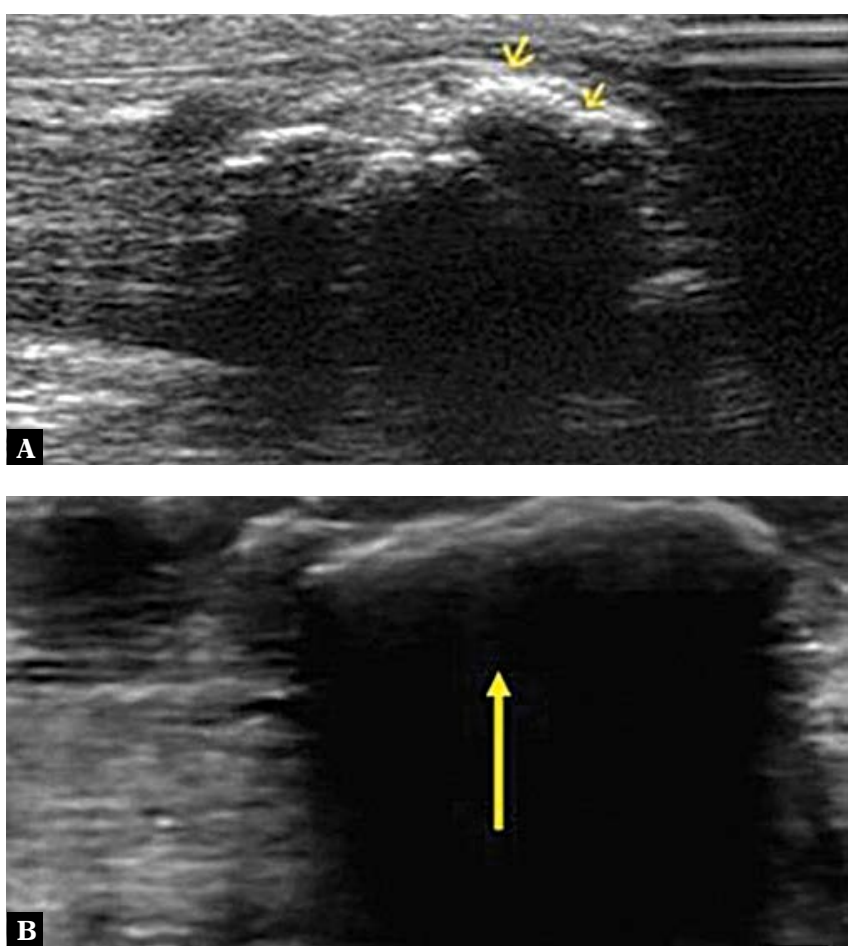

Fig. 3. US image of a 46-year-old male patient shows thickening of the Achilles tendon proximal to the insertion with multiple arc-like echogenic foci showing distal acoustic shadowing (arrows in $\mathbf{A}$ ); suggestive of calcific tendinosis. US in another female patient aged 41 years shows a large echogenic focus in the Achilles tendon near the insertion showing dense acoustic shadowing

\section{Normal US appearance of tendons and ligaments}

Tendons show fascicular pattern as echogenic lines on long axis images and dot pattern on short axis images. Ligaments show similar appearance on ultrasonography, but are less echogenic than tendons. Ligaments and tendons both exhibit anisotropy on ultrasound, which may simulate pathology ${ }^{(8)}$.

\begin{tabular}{|c|c|}
\hline Compartment & Tendons/ligaments \\
\hline Anterior & $\begin{array}{l}\text { Anterior tibial tendon } \\
\text { Extensor hallucis longus tendon } \\
\text { Extensor digitorum longus tendon }\end{array}$ \\
\hline Posterior & $\begin{array}{l}\text { Achilles tendon } \\
\text { Plantaris tendon }\end{array}$ \\
\hline Lateral & $\begin{array}{l}\text { Peroneus longus tendon } \\
\text { Peroneus brevis tendon }\end{array}$ \\
\hline Medial & $\begin{array}{l}\text { Posterior tibial tendon } \\
\text { Flexor digitorum longus tendon } \\
\text { Flexor hallucis longus tendon }\end{array}$ \\
\hline $\begin{array}{l}\text { The lateral ligament } \\
\text { complex }\end{array}$ & $\begin{array}{l}\text { Anterior talofibular } \\
\text { Posterior talofibular } \\
\text { Calcaneofibular }\end{array}$ \\
\hline $\begin{array}{l}\text { The medial ligament } \\
\text { complex }\end{array}$ & $\begin{array}{l}\text { Tibionavicular } \\
\text { Tibiospring } \\
\text { Tibiocalcaneal } \\
\text { Anterior tibiotalar } \\
\text { Posterior tibiotalar }\end{array}$ \\
\hline Ankle syndesmosis & $\begin{array}{l}\text { Anterior inferior tibiofibular } \\
\text { Posterior inferior tibiofibular } \\
\text { Inferior transverse } \\
\text { Distal interosseous }\end{array}$ \\
\hline The sinus tarsi & $\begin{array}{c}\text { Cervical and interosseous talocalcaneal } \\
\text { ligaments Neurovascular structures } \\
\text { Fat }\end{array}$ \\
\hline The tarsal tunnel & $\begin{array}{l}\text { Flexor digitorum longus tendon } \\
\text { Posterior tibial tendon } \\
\text { Flexor hallucis longus tendon } \\
\text { Neurovascular bundle }\end{array}$ \\
\hline
\end{tabular}

Tab. 2. The normal tendo-ligamentous anatomy of the ankle joint

Appearance of common ankle pathologies on US

\section{Ligament pathology}

Ultrasound of an acute ligament sprain may show thickening of the ligament with diffuse hypoechogenicity and surrounding fluid. A tear may appear as a hypoechoic or anechoic area interrupting the ligament fibers, and ex- 
tends across the ligament in a full-thickness complete tear (Fig. 1, Fig. 2). As the ligament heals, the fluid disappears but the ligament may remain thickened and laxity may be demonstrated on dynamic imaging ${ }^{(8,9)}$.

\section{Tendon pathologies}

Tendinosis

Ultrasound of tendinosis typically shows loss of the normal fibrillar structure with increased spacing of the hyperechoic fibrillar lines. The tendon appears thick and hypoechoic. Calcific tendinosis presents as a thickened tendon with diffuse or scattered echogenic foci showing distal acoustic shadowing (Fig. 3).

\section{Tenosynovitis}

Acute tenosynovitis appears as anechoic fluid in the tendon sheath and can occur with or without tendinitis (Fig. 4).

\section{Tendon tears}

Full-thickness tears are diagnosed as a gap in a tendon that is filled with hematoma in the acute setting and with scar or granulation tissue in chronic cases. Retraction of the proximal and distal ends can be visualized in a complete tear. Partial tears appear as an incomplete disruption of the fibrillar echotexture of the tendon (Fig. 5, Fig. 6).

\section{Joint effusion}

A small amount of fluid may accumulate at the talar neck, without any significant effusion in the anterior joint recess. However mild to moderate joint fluid may displace the hyperechoic anterior fat pad in the anterior joint recess. (Fig. 7).

\section{Material and methods}

Included in the study were 136 patients with a history of ankle pain. All were subjected to detailed clinical history and local examination.

\section{Patient inclusion criteria}

Patients of all age groups and of either sex who presented with ankle pain were included in the study.

\section{Patient exclusion criteria}

Patients with known or diagnosed fracture/degenerative changes on plain radiographs of the ankle were excluded.
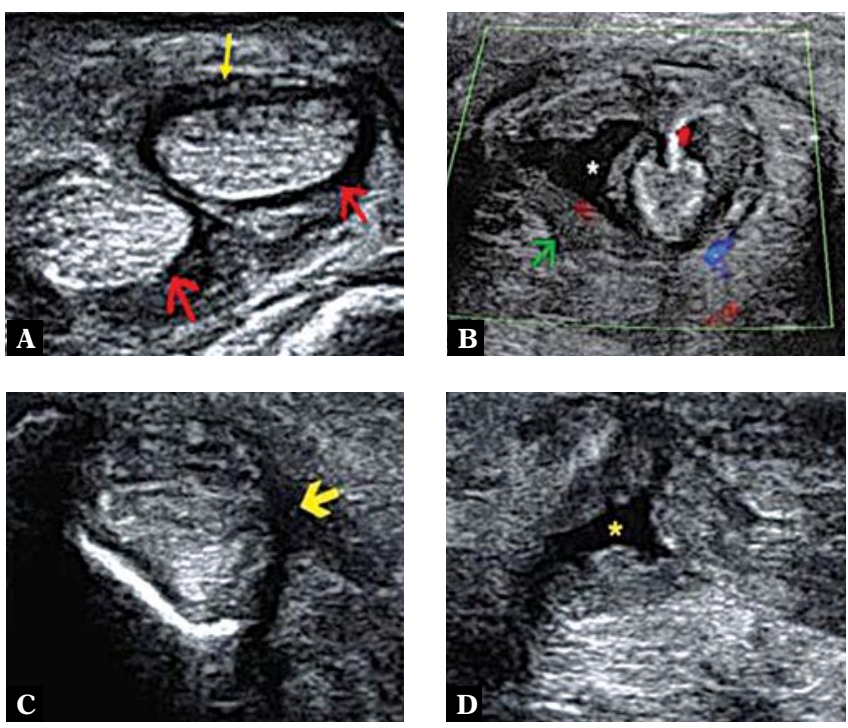

Fig. 4. US image of a 33-year-old female patient with a history of lateral ankle pain for the last 16 days shows thickened and hypoechoic tendon sheath around the peroneus longus and brevis tendons (red and yellow arrows in $\mathbf{A}$ ). Another female patient aged 48 years presented with a history of medial ankle pain. US shows tendon sheath thickening of the tibialis posterior tendon (green arrow in $\mathbf{B}$ and yellow arrow in $\mathbf{C}$ ) with increased vascularity on color Doppler imaging (B); suggestive of tenosynovitis. Asterisk presents free fluid (B, D). Point tenderness was present in both cases
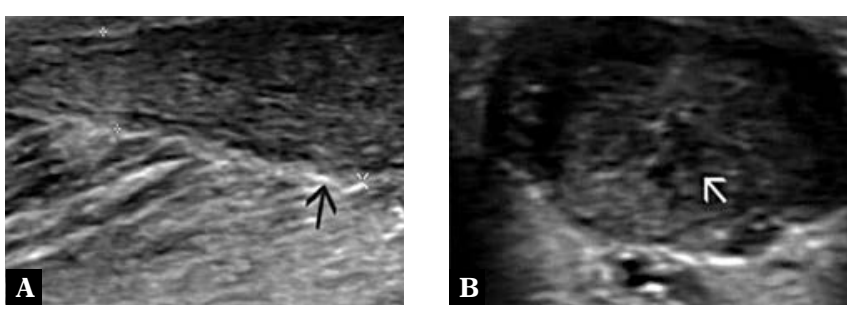

Fig. 5. A 34-year-old male patient presented with a history of sudden acute pain in the posterior aspect of the lower leg while running, 17 days back. US image in the sagittal plane shows thickened and hypoechoic Achilles tendon (arrow in A). A tiny echopoor area is observed in the axial plane (arrow in $\mathbf{B}$ ), consistent with type 1 tear

\begin{tabular}{|l|c|c|c|}
\hline Pathology & Males & Females & Total \\
\hline Achilles tendon tear & 38 & 10 & 48 \\
\hline Ligament injury & 38 & 16 & 54 \\
\hline Tenosynovitis & 12 & 28 & 40 \\
\hline $\begin{array}{l}\text { Achilles tendon } \\
\text { calcification }\end{array}$ & 8 & 6 & 14 \\
\hline Joint effusion & 18 & 22 & 40 \\
\hline Miscellaneous pathologies & 14 & 8 & 22 \\
\hline
\end{tabular}

Tab. 3. Sex-wise incidence of ankle pathologies diagnosed in the study 


\begin{tabular}{|c|c|c|c|}
\hline Type of pathology (number) & Positive on us (\%) & Positive on clinical tests (\%) & $P$ value \\
\hline Achilles tendon tear (48) & $48(100.0)$ & $44(91.7)$ & 0.125 \\
\hline • Type I (18) & 18 & 4 & \\
\hline • Type II (14) & 14 & 14 & \\
\hline • Type III (10) & 10 & 10 & \\
\hline • Type IV (6) & 6 & 6 & \\
\hline Ligament injury (54) & $44(81.5)$ & $46(85.2)$ & 0.815 \\
\hline - ATFL injury (36) & & & \\
\hline GRADE II & 20 & 14 & \\
\hline GRADE III & 16 & 14 & \\
\hline - CFL INJURY (10) & 0 & & \\
\hline 1. Grade II (8) & 6 & 8 & \\
\hline 2. Grade III (2) & 2 & 2 & \\
\hline • PTFL injury (8) & 0 & 8 & \\
\hline Tenosynovitis (40) & $38(95.0)$ & $38(95.0)$ & 1.00 \\
\hline - Tibialis posterior (16) & 14 & 16 & \\
\hline - Peroneus longus (12) & 12 & 12 & \\
\hline - Peroneus brevis (10) & 10 & 10 & \\
\hline - Extensor hallucis longus (2) & 2 & 0 & \\
\hline Achilles tendon calcification (14) & $14(100.0)$ & $8(57.1)$ & 0.031 \\
\hline Joint effusion (40) & $40(100.0)$ & $26(65.0)$ & 0.000 \\
\hline Miscellaneous pathologies (22) & $22(100.0)$ & $16(72.7 .0)$ & 0.031 \\
\hline - Hemangioma (8) & 8 & 6 & \\
\hline - Foreign body abscess (6) & 6 & 4 & \\
\hline - Granulomatous lesion (4) & 4 & 2 & \\
\hline - Soft tissue mass (4) & 4 & 4 & \\
\hline Total (218) & $206(94.0)$ & $178(82.0)$ & 0.000 \\
\hline
\end{tabular}

Tab. 4. Comparison of ultrasonography and clinical findings in ankle pathologies in the study 

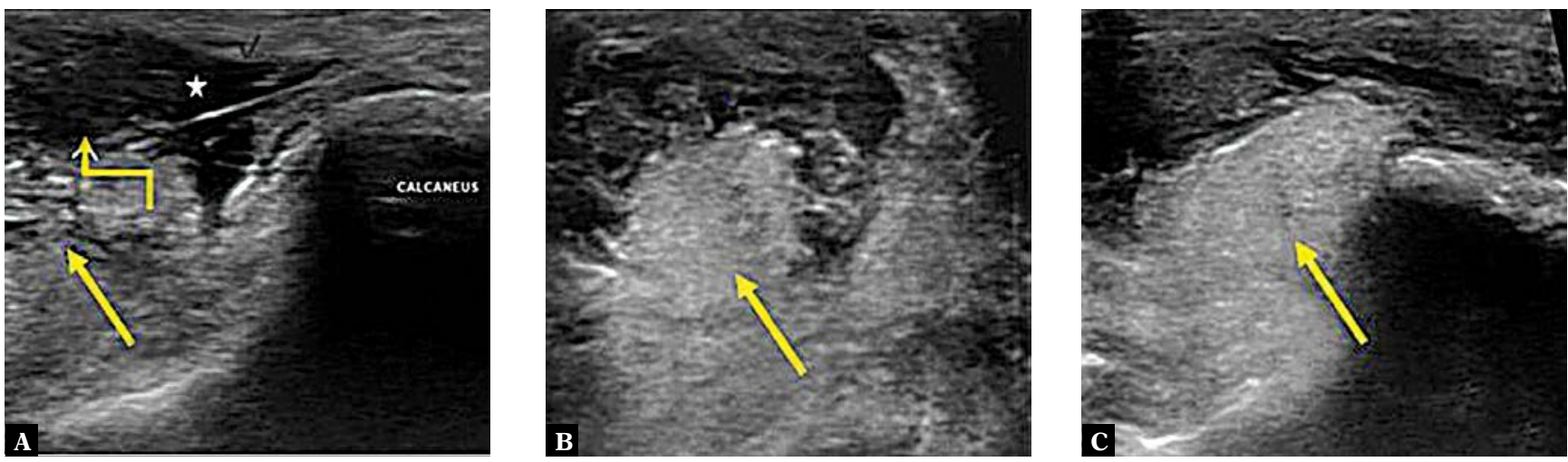

Fig. 6. A 19-year-old male patient presented with a history of injury with glass in the lower leg posteriorly 3 days back. US image showing thickened, hypoechoic and retracted Achilles tendon (elbow arrow in A). Anechoic fluid is seen in gap (asterisk in $\mathbf{A}$ ); suggestive of type 2 tear. Another 28-year-old male patient presented with a history of injury with some sharp object in the lower leg posteriorly 7 days back. US image showing thickened, hypoechoic and retracted Achilles tendon with echogenic Kager's fat pad seen herniating into the gap (arrow in $\mathbf{B}, \mathbf{C}$ ); suggestive of type 3 tear

\section{Statistical analysis}

Data collected were analyzed using SPSS software version 22 and the valid conclusions were drawn. McNemar test was used to compare the ultrasonography and clinical findings in ankle pathologies. $\mathrm{p}<0.05$ and $\mathrm{p}<0.01$ were considered to be significant and highly significant, respectively.

\section{Sonography technique}

Ultrasonography was performed using the Voluson E8 Expert BT09 scanner (Wipro GE Healthcare, Bengaluru, India) with SP10-16-D wide-band linear transducer with the frequency of 7-18 MHz. Ultrasonography of the ankle was performed, using the European Society of Musculoskeletal Radiology (ESSR) guidelines.

\section{Results}

All the patients were evaluated for age, sex distribution, and clinical presentation. Two hundred and eighteen pathologies were diagnosed. Of these, 178 pathologies were clinically suspected, but 206 were diagnosed with ultrasonography.

Most of the patients were in the age group of 16-30 years (42.64\%) with the range from 15-70 years. With regard to pathology, tenosynovitis and joint effusion were more common in female patients than in male patients, and there was a male preponderance for Achilles tendon and ligamentous pathologies (Tab. 3). Right ankle involvement was more common than the left side in both sexes. Approximately $55 \%$ of patients presented with an acute history, followed by chronic symptoms in $29 \%$, and subacute symptoms in the remaining patients. With regard to clinical features, all patients presented with pain, followed by swelling (55\% of patients) and movement restriction (34\% of patients). Point tenderness could be elicited in $70 \%$ of patients, with trauma being the cause of symptoms in $48 \%$ of patients.
Cases of Achilles tendon tear were clinically suspected in all patients with a US diagnosis of a full-thickness tear. However, out of 18 patients for whom US revealed a partial-thickness tear, only 14 were clinically suspected. For cases of Achilles tendon calcification, joint effusion, and miscellaneous pathologies of the ankle joint, US diagnosed more pathologies as compared with the clinical examination (Tab. 4).

Thirty-eight patients with clinical suspicion of tenosynovitis were diagnosed with US. However, it was not possible to diagnose tenosynovitis on US in 2 patients who were clinically suspected.

Thirty-eight patients were clinically suspected of having a lateral ligament injury. US detected injury in all these patients, and also diagnosed 6 more patients for whom a clinical suspicion was absent. In cases of anterior talofibular ligament (ATFL) injury, 4 patients were clinically diagnosed with grade II injury. However, by conducting the ultrasound anterior drawer test, the injury was upgraded to grade III. Eight patients with positive posterior drawer test results were sent for US. However, posterior talofibular ligament (PTFL) pathology could not be found in these patients.
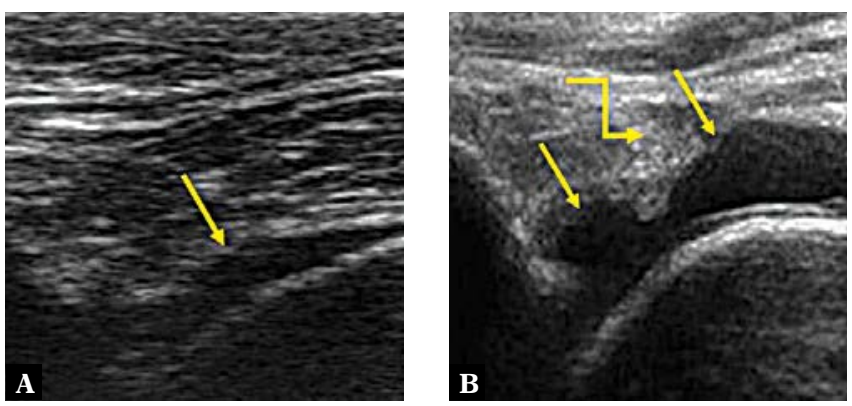

Fig. 7. US images in 2 different patients show anechoic fluid collections in the anterior recess of the tibiotalar joint (yellow arrows in $\mathbf{A}$ and $\mathbf{B})$. The echogenic fat pad is displaced anteriorly (elbow arrow in $\mathbf{B}$ ) 

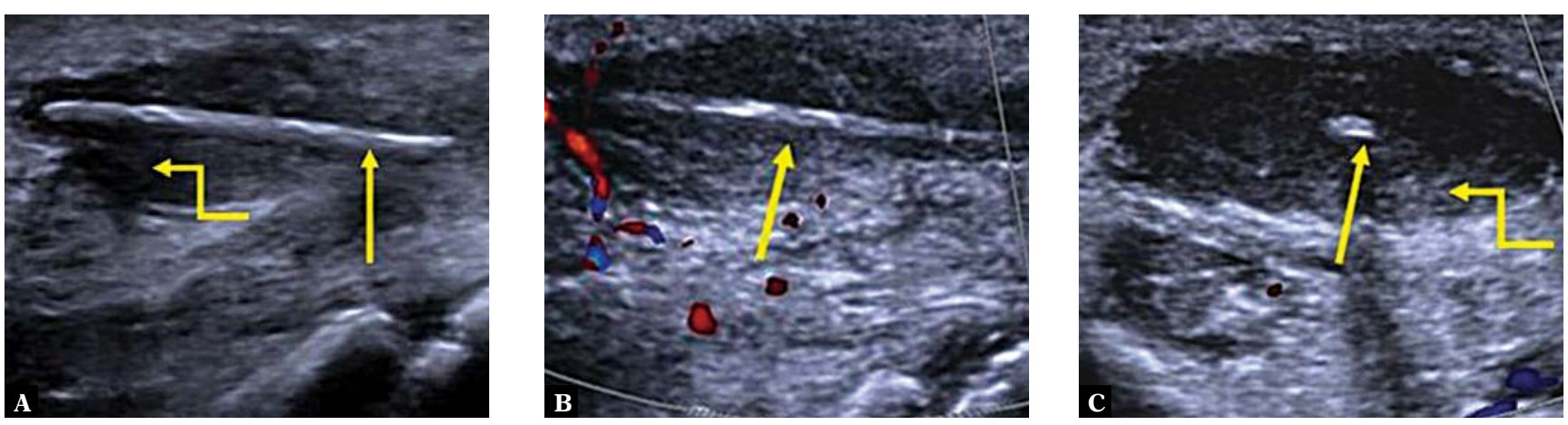

Fig. 8. A. US image in the longitudinal plane demonstrating an echogenic subcutaneous structure (yellow arrow) surrounded by a hypoechoic collection (elbow arrow). B, C. Color Doppler images in the longitudinal and transverse planes show increased local vascularity; suggestive of foreign body with surrounding granulomatous tissue. Follow-up revealed a wooden foreign body

\section{Discussion}

In our study, $64.9 \%$ of patients were in the young age group. Similar results were reported in studies by Rubin et al. and Pugia et al. in which most patients were in the young age group, with the mean age varying from 30 to 40 years $^{(10,11)}$.

Male patients outnumbered female patients in our study. A male predominance was similarly reported in studies by Pugia et al. ${ }^{(11)}$.

No time interval was specified for the inclusion of the participants in our study. Most (62.8\%) patients underwent a radiological workup within 3 months of the onset of symptoms $(40.0 \%$ within 1 month and $22.8 \%$ within 1-3 months), whereas $37.2 \%$ of patients presented with chronic ankle pain ( $>3$ months). All patients in our study presented with ankle pain. The most common associated symptom was ankle swelling, which was observed in $65.8 \%$ of the patients. This finding is in close agreement with the study conducted by Carretta et al. in which $56.7 \%$ of their patients underwent imaging because of acute pain and swelling, and $43.3 \%$ due to chronic symptoms ${ }^{(12)}$.

In our study, the patients with tendon abnormalities as the cause of ankle pain outnumbered the patients with other abnormalities, and similar incidence was described in a study by Artul et al. ${ }^{(13)}$.

In our study, we found that Achilles tendon tear was the most common tendon injury, and similar findings were described by Ibrahim et al. ${ }^{(14)}$.

In our study, clinical tests were positive in approximately $92 \%$ of the cases with Achilles tendon tear. Kauwe et al. also stated that physical examination has high sensitivity and specificity for Achilles tendon tear ${ }^{(15)}$.

Ultrasonography was also able to detect 2 additional patients with Achilles tendon tear for whom clinical suspicion was absent. Moreover, differentiating a full-thickness tear from a partial-thickness tear was possible with ultrasound. Kayser et al. in his study was also able to use ul- trasonography for differentiating full-thickness tears from partial-thickness tears or tendinosis of the Achilles tendon with $92 \%$ accuracy ${ }^{(16)}$.

Of 12 patients with partial-thickness tear of the Achilles tendon, US was possible to detect 4 of these patients by taking advantage of the dynamic nature of US. In these patients, dorsiflexion of the foot demonstrated a partialthickness tear, which was initially mistaken for tendinosis of the Achilles tendon clinically. Kayser et al. demonstrated a partial break in the tendon continuity by using forced dynamic ultrasound assessment ${ }^{(16)}$.

Ultrasonography in our study was also able to characterize the type of Achilles tendon tear according to the clinical classification, which is a guide for deriving a graded and differentiated therapy from a broad spectrum of treatments ${ }^{(17)}$.

In our study, 14 patients had calcification in the Achilles tendon, based on US findings. Taki et al. also suggested that US could perform well in depicting calcifications $^{(18)}$

Tenosynovitis was more common in female individuals than in male individuals in our study. These findings were similar to those of El-Liethy and $\mathrm{Kamal}^{(19)}$. In 2 patients who were not suspected of having tenosynovitis it was possible to detect it on US. Similar results were shown by Pereira et al. They found high concordance between the clinical and US findings in almost all patients with ankle tenosynovitis $^{(20)}$. In addition, color Doppler demonstrated increased vascularity in patients that had been diagnosed with tenosynovitis on US, which was stated by Park et al. ${ }^{(21)}$.

El-Liethy and Kamaland Grassi et al. also concluded that, compared with MRI, US has $100 \%$ sensitivity for tendon pathologies and no further investigation is required $^{(19,22)}$.

In our study, ATFL injuries outnumbered other ligamentous injuries. Rosenberg et al. also mentioned that ATFL is 
the most commonly injured ligament in the ankle because it is the weakest ankle ligament ${ }^{(23)}$. Ultrasonography also made it possible to diagnose 8 additional patients with an ATFL injury in whom clinical suspicion was absent. Croy et al. indicated that clinical examination has low reliability and diagnostic accuracy in determining ligament injuries of the ankle, especially partial-thickness tears ${ }^{(24)}$.

In our study, differentiating between grades of injury was also possible with US, with similar results shown by Cheng et al. and Radwan et al. ${ }^{(25,26)}$.

In our study, the ATFL injury grade was changed from II to III in 4 patients by performing the US anterior drawer test. Sconfienza et al. stated that dynamic maneuvers may be used to increase the diagnostic accuracy of detecting tears and to differentiate a partial tear from a complete tear ${ }^{(27)}$.

In our study, US was not helpful in detecting the clinically suspected PTFL pathology in any patient. Park et al. have mentioned that PTFL is difficult to visualize on US ${ }^{(21)}$.

There was no patient with syndesmotic injury or medial ligament injury in our study. This finding may be attributed to the small sample size and also to the fact that these are far less common than lateral ligament injuries ${ }^{(28)}$.

Chiang et al. demonstrated that the use of ultrasound is limited in detecting bony pathologies ${ }^{(29)}$. For these cases, MRI remains the gold standard ${ }^{(3)}$.

\section{References}

1. Haaga J: Computed tomography and magnetic resonance imaging of the whole body. Mosby, Philadelphia 2009.

2. Kumar S, Verma V, Singh H, Rawat A: Spectrum of high-resolution sonographic findings in painful ankle and foot. Astrocyte 2017; 3: 213-220.

3. Alazzawi S, Sukeik M, King D, Vemulapalli K: Foot and ankle history and clinical examination: A guide to everyday practice. World J Orthop 2017; 8: 21-29.

4. Szczepaniak J, Ciszkowska-Łysoń B, Śmigielski R, Zdanowicz U: Value of ultrasonography in assessment of recent injury of anterior talofibular ligament in children. J Ultrason 2015; 15: 259-266.

5. Thompson TC, Doherty JH: Spontaneous rupture of tendon of Achilles: A new clinical diagnostic test. J Trauma 1962; 2: 126-129.

6. Saenz R, Ries S, Giese J, Knapp D: MRI of ankle and hindfoot pain. J Am Osteopath Coll Radiol 2015; 4: 5-15.

7. Blankstein A: Ultrasound in the diagnosis of clinical orthopedics: The orthopedic stethoscope. World J Orthop 2011; 2: 13-24.

8. Precerutti M, Bonardi M, Ferrozzi G, Draghi F: Sonographic anatomy of the ankle. J Ultrasound 2013; 17: 79-87.

9. Hua Y, Yang Y, Chen S, Cai Y: Ultrasound examination for the diagnosis of chronic anterior talofibular ligament injury. Acta Radiol 2012; 53: 1142-1145.

10. Rubin DA, Tishkoff NW, Britton CA, Conti SF, Towers JD: Anterolateral soft-tissue impingement in the ankle: Diagnosis using MR imaging. AJR Am J Roentgenol 1997; 169: 829-835.
In our study, US was able to detect tendo-ligamentous pathologies, as well as miscellaneous pathologies, such as hemangiomas, foreign body abscesses, granulomatous lesions, and soft tissue masses (Fig. 8).

\section{Conclusion}

Ultrasonography is an excellent tool for evaluating patients with ankle pain, especially in cases of lateral ligament pathologies, tendinous pathologies, joint effusion, and miscellaneous pathologies. It can be used as the primary imaging investigation because it allows a rapid, dynamic, and costeffective examination of the ankle joint. However, ultrasonography has limitations when using it to evaluate a suspected PTFL injury, marrow abnormalities, and deep seated pathologies, for which MRI should be incorporated for a diagnosis.

\section{Conflict of interest}

All the authors declare that they have no conflict of interest.

\section{Acknowledgement}

I would like to thank Dr. Sukhdeep Kaur (assistant professor, Department of Pediatrics, SGRDUHS, Sri Amritsar) for data gathering and Dr. Harpreet Kaur (biostatistician. SGRDUHS, Sri Amritsar) for help in statistical analysis in the study.

11. Pugia M, Middel C, Seward S, Pollock J, Hall R, Lowe L et al:: Comparison of acute swelling and function in subjects with lateral ankle injury. J Orthop Sports Phys Ther 2001; 31: 384-388.

12. Carretta G, De Nicola T, Gongolo R, Villabruna M: [Magnetic resonance imaging in tendon and ligament injuries of ankle. Our personal experience]. Radiol Med 1996; 91: 563-569.

13. Artul S, Habib G: Ultrasound findings of the painful ankle and foot. J Clin Imaging Sci 2014; 4: 25-29.

14. Ibrahim NM, Elsaeed HH: Lesions of the Achilles tendon: Evaluation with ultrasonography and magnetic resonance imaging. J Clin Imaging Sci 2013; 44: 581-587.

15. Kauwe M: Acute Achilles tendon rupture: Clinical evaluation, conservative management, and early active rehabilitation. Clin Podiatr Med Surg 2017; 34: 229-243.

16. Kayser R, Mahlfeld K, Heyde CE: Partial rupture of the proximal Achilles tendon: A differential diagnostic problem in ultrasound imaging. $\mathrm{Br}$ J Sports Med 2005; 39: 838-842.

17. Amlang M, Zwipp H, Friedrich A, Peaden A, Bunk A, Rammelt S: Ultrasonographic classification of Achilles tendon ruptures as a rationale for individual treatment selection. ISRN Orthop 2011; 2011: 869703.

18. Taki H, Sakamoto T, Yamakawa M, Shiina T, Nagae K, Sato T: Small calcification depiction in ultrasound B-mode images using decorrelation of echoes caused by forward scattered waves. J Med Ultrason 2011; 38: 73-80. 
19. El-Liethy N, Kamal H: High resolution ultrasonography and magnetic resonance imaging in the evaluation of tendino-ligamentous injuries around ankle joint. The Egyptian Journal of Radiology and Nuclear Medicine 2016; 47: 543-555.

20. Pereira ALN, dos Santos Pastori M, dos Santos Vianna de Matos Leite N, Rombaldi Pereira T, Thais Kawamoto T, Kefler Ferreira K et al.: Ankle tenosynovitis in rheumatoid arthritis: Clinical and ultrasonographic evaluation. Revista da Faculdade de Ciências Médicas de Sorocaba 2016; 18: 161-164.

21. Park JW, Lee SJ, Choo HJ, Kim SK, Gwak HC, Lee SM: Ultrasonography of the ankle joint. Ultrasonography 2017; 36: 321-335.

22. Grassi W, Lamanna G, Farina A, Cervini C: Synovitis of small joints: sonographic guided diagnostic and therapeutic approach. Ann Rheum Dis 1999; 58: 595-597.

23. Rosenberg Z, Beltran J, Bencardino J: From the RSNA Refresher Courses. Radiological Society of North America. MR imaging of the ankle and foot. Radiographics 2000; 20 (Spec No): S153-S179.

24. Croy T, Koppenhaver S, Saliba S, Hertel J: Anterior talocrural joint laxity: Diagnostic accuracy of the anterior drawer test of the ankle. J Orthop Sports Phys Ther 2013; 43: 911-919.

25. Cheng Y, Cai Y, Wang Y: Value of ultrasonography for detecting chronic injury of the lateral ligaments of the ankle joint compared with ultrasonography findings. Br J Radiol 2014; 87: 20130406.

26. Radwan A, Bakowski J, Dew S, Greenwald B, Hyde E, Webber N: Effectiveness of ultrasonography in diagnosing chronic lateral ankle instability: A systematic review. Int J Sports Phys Ther 2016; 11: 164-174.

27. Sconfienza L, Orlandi D, Lacelli F, Serafini G, Silvestri E: Dynamic high-resolution US of ankle and midfoot ligaments: normal anatomic structure and imaging technique. Radiographics 2015; 35: 164-178.

28. Milz P, Milz S, Steinborn M, Mittlmeier T, Putz R, Reiser M: Lateral ankle ligaments and tibiofibular syndesmosis: 13-MHz high-frequency sonography and MRI compared in 20 patients. Acta Orthop Scand 1998; 69: 51-55.

29. Chiang Y, Wang T, Hsieh S: Application of ultrasound in sports injury. J Med Ultrasound 2013; 21: 1-8. 